\title{
MIR30A Gene
}

National Cancer Institute

\section{Source}

National Cancer Institute. MIR30A Gene. NCI Thesaurus. Code C80747.

This gene is involved in the regulation of gene expression. While it has no known role in oncogenesis, MIR30A plays a role in the development of glomerular disease. 